\title{
Compliance Boundaries for Multiple-Frequency Base Station Antennas in Three Directions
}

\author{
Arno Thielens, Günter Vermeeren, Divya Kurup, Wout Joseph, and Luc Martens \\ (email:arno.thielens@intec.UGent.be, tel : +32 933 14918, fax:+32 933 14899) \\ Department of Information Technology, \\ Ghent University / Interdisciplinary Institute for Broadband Technology (IBBT) \\ Gaston Crommenlaan 8, B-9050 Ghent, Belgium
}

Running title: Compliance Boundaries for Multiple-Frequency Base Station Antennas

Abstract- In this paper, compliance boundaries and allowed output powers are determined for the front, back and side of multiple-frequency base station antennas, based on the rootmean-squared electric field, the whole-body averaged specific absorption rate (SAR), and the $10 \mathrm{~g}$ averaged SAR in both the limbs and the head and trunk. For this purpose, the basic restrictions and reference levels defined by the International Commission on NonIonizing Radiation Protection (ICNIRP) for both the general public and occupational exposure are used. The antennas are designed for: Global System for Mobile Communications around 900MHz (GSM900), GSM1800, High Speed Packet Access (HSPA), and Long Term Evolution (LTE) and are operated with output powers at the individual frequencies up to $300 \mathrm{~W}$. The compliance boundaries are estimated using finite-difference time-domain simulations with the Virtual Family Male and have been determined for three 
directions with respect to the antennas for $800,900,1800$ and $2600 \mathrm{MHz}$. The reference levels are not always conservative when the radiating part of the antenna is small compared to the length of the body. Combined compliance distances, which ensure compliance with all reference levels and basic restrictions, have also been determined for each frequency. A method to determine a conservative estimation of compliance boundaries for multiplefrequency (cumulative) exposure is introduced. Using the errors on the estimated allowed powers, an uncertainty analysis is carried out for the compliance distances. Extrapolation errors are estimated to be smaller than $41 \%$, while uncertainties on the compliance distances are found to be smaller than $122 \%$.

Key Words- Base station antennas, specific absorption rate SAR, compliance boundaries, allowed output powers 


\section{INTRODUCTION}

Base station antennas (BSAs) can be approached by the general population and instructed workers. Both categories thus have to be protected from possible radiofrequency (RF) induced health effects. To this aim compliance boundaries based on the International Commission on Non-Ionizing Radiation Protection's (ICNIRP) basic restrictions on the whole-body averaged specific absorption rate (SAR), peak 10g averaged SAR and electric field (reference levels) are determined [ICNIRP, 1998]. A standard for the evaluation of RF compliance near BSAs has also been issued by the International Electrotechnical Commission [IEC, 2011].

Earlier studies like Bernardi et al. [2000], Cooper et al. [2002], Joseph et al. [2005], Lacroux et al. [2008], and Gosselin et al. [2009] aim at evaluating SAR and electric fields in the proximity of a BSA. In these studies, compliance distances were determined in the direction of the antenna's main lobe, using measurements or simulations of electric fields. More recent studies also consider other directions towards the antenna [Thors et al., 2008] and use the Virtual Family for compliance simulations [Gosselin et al., 2011]. This last study also developed formulas to estimate SAR values or compliance distances using the antenna. A large study has determined the SAR at different sides (front and back) of the antenna, for several generic antenna types (modeled as dipole arrays) and single frequency exposure conditions in a region of 0.3-5 GHz [Vermeeren et al., 2010; Gosselin et al., 2011]. The influence of a reflective environment around the phantom has also been studied in Bernardi et al. [2000] and Vermeeren et al. [2010]. Recently, Long Term Evolution (LTE) BSAs, emitting at 800 and $2600 \mathrm{MHz}$, and multiple-frequency BSAs have been developed and are now in use [3GPP, 2009]. Yet, up till now no full assessment of the compliance boundaries around these antennas has been done. The exposure caused by these 
BSAs was already studied in Cecil et al. [2011], but only for one direction and single frequency operation.

The objective of this study is to numerically investigate and compare compliance boundaries based on the ICNIRP basic restrictions on the whole body averaged SAR, the peak $10 \mathrm{~g}$ localized SAR and electric field (reference levels) [ICNIRP, 1998]. The novelties of this study are the following. The compliance boundaries are determined for both the general public and occupational exposure in the vicinity of typical multiple-frequency BSAs. To this aim the BSAs are placed near the heterogeneous Virtual Family Male (VFM) [Christ et al., 2010]. We provide, for the first time, an uncertainty analysis of the compliance boundaries, using recently determined simulation errors for the VFM. Furthermore, we consider three directions for the VFM's placement with respect to the BSAs, namely, at the front, at the back and at the side of the BSA. The antennas are operated at 4 frequencies $(800 \mathrm{MHz}, 900 \mathrm{MHz}, 1800 \mathrm{MHz}$, and $2600 \mathrm{MHz}$ ), where both single frequency and cumulative exposure are considered. These compliance boundaries are compared with realistic output powers emitted by the BSAs in operation, which range up to $300 \mathrm{~W}$ at a single frequency. Note that compliance boundaries have not yet been determined for the single LTE frequencies of $800 \mathrm{MHz}$ and $2600 \mathrm{MHz}$ in other studies. The cumulative exposure scenarios have also not been investigated before.

These results are important for mobile phone operators that wish to use similar antennas and are looking for compliance boundaries when installing them. Not only the network providers, but also (local) authorities that wish to protect the general public can benefit from these results. Workers that have to perform maintenance on these of antennas are also of mayor concern to the operators, who need to know whether an RF worker can approach a BSA from the back or side without exceeding the ICNIRP basic restrictions. 


\section{MATERIALS AND METHODS}

\section{Configuration of the base station antennas and the Virtual Family Male}

Models are made for three real multiple-frequency BSAs. Table 1 lists the characteristics, operating frequencies and powers of the BSAs. Figure 1 shows a schematic drawing of these antennas, which consist of arrays of patch antennas. The full length of the antennas is equipped with patch antennas emitting at 800 and $900 \mathrm{MHz}$. The upper part of the antennas also emits at $2600 \mathrm{MHz}$, while the lower half of the BSA is designed to operate at $1800 \mathrm{MHz}$. All the antennas are cross polarized. Antennas with different lengths, gains, vertical and horizontal beam widths are considered to provide generally usable results.

The Virtual Family Male (VFM) [Christ et al., 2010], selected to carry out the finite-difference time-domain (FDTD) simulations, is a three-dimensional human-body model or phantom, based on magnetic resonance images (MRI) of a healthy volunteer. This adult model has a mass of $72.2 \mathrm{~kg}$, a height of $1.80 \mathrm{~m}$ and consists of 81 different tissues. The dielectric properties of the body tissues have been taken from the Gabriel database [Gabriel et al., 1996]. The VFM is placed in the proximity of the BSAs, where the horizontal distance between the VFM and a BSA is measured between the anterior face of the bounding box (BB) of the VFM (a brick surrounding the VFM, with each face perpendicular to the main axes and tangent to the VFM in the extreme point of the VFM in that direction, with dimensions $282 \times 540 \times 1804 \mathrm{~mm}^{3}$ ) and the proximal face of the BB of the BSA, as shown in Figure 1. A separation of $0 \mathrm{~mm}$ is defined as the distance where the anterior face of the VFM's bounding box is at $16 \mathrm{~mm}$ distance of the proximal face of the BSA's BB, this to ensure that there is no contact between the VFM and the BSA. Figure 1 shows that the center of the VFM's BB box is vertically aligned to the center of the whole BSA. 
Although some frequencies only use a part of the antenna to be emitted from, this alignment is chosen for all frequencies. Figure 2 shows the three different configurations that have been studied. The VFM is always facing the BSA and is placed in front of the BSA, at the side of the BSA or behind the BSA. The VFM is then moved away from the BSA along the respective direction over distances $d_{\text {front }}, d_{\text {side }}$ and $d_{\text {back }}$.

\section{Methodology}

The compliance boundaries are assessed numerically, using the FDTD method. When compared to other numerical techniques, the FDTD method easily models bodies with complex material distributions, such as large inhomogeneous human-body models, without increasing largely the computational expenses [Hand, 2008]. We have selected the commercially available tool SEMCAD (SPEAG, Zürich Switzerland) for the FDTD computations. The maximum grid step inside the VFM is chosen to be $2 \mathrm{~mm}$, in order to ensure accurate SAR results. We found deviations smaller than $5 \%$ on the whole-body averaged SAR $\left(\mathrm{SAR}_{\mathrm{wb}}\right)$ and peak $10 \mathrm{~g}$ averaged SAR $\left(\mathrm{SAR}_{10 \mathrm{~g}}\right)$ values for a larger grid step of $2 \mathrm{~mm}$, compared to a grid step of $1 \mathrm{~mm}$ at $2600 \mathrm{MHz}$. These small deviations are acceptable, taking into account that a grid step of $1 \mathrm{~mm}$ at $2600 \mathrm{MHz}$ would lead to an enormous amount of grid cells in the simulation domain. Uni-axial perfectly matched layers are applied at the edges of the simulation domain to avoid reflections back into the simulation domain.

Two types of simulations are carried out. First electric fields surrounding the antennas are calculated, using FDTD simulations with only the selected BSA present. The root-mean-square (RMS) electric field $E_{\mathrm{rms}}$ surrounding the antenna is then averaged over a volume where the bounding box of the phantom would be. Secondly, the SAR in the VFM is determined with 
FDTD simulations using the configuration shown in Figures 1 or 2, where both the BSA and the VFM are present.

If there is a large separation between the VFM and the BSA, the FDTD algorithm will assign an enormous amount of cells to the air between the antenna and the body. Running such a simulation is very time consuming and poses high memory requirements on the hardware that is used for the computations. Therefore a hybrid technique, called the "Generalized Huygens' Box Method" (GHBM), is used for the larger configurations (separation $\geq 2 \mathrm{~m}$ ) [Vermeeren et al., 2010; Gosselin et al., 2011]. The GHBM is a two-step method where in a first step, the incident fields on a closed box (GHB) surrounding the human body model are computed and in a second step, FDTD is used to simulate the SAR inside a human body model using the complex incident fields on the GHB around the human body model as excitation. The placement of the GHB is illustrated in Figures 1 and 2. The GHBM is based on the assumption that the coupling between the human body and the BSA can be neglected.

After determination of the SAR values in the phantom, values for the $\mathrm{SAR}_{\mathrm{wb}}$ and the maximum of the $\mathrm{SAR}_{10 \mathrm{~g}}$-both in the limbs ( $\left.\mathrm{SAR}_{10 \mathrm{~g}, \text { limbs }}\right)$ and in the trunk and head ( $\left.\mathrm{SAR}_{10 \mathrm{~g}, \text { trunk }}\right)$ - can be calculated. As the output power $\left(\mathrm{P}_{\text {out }}\right)$ of the antenna is known and the phantom is moved away from the front, the side and the back of the antenna, this leads to relationships $E_{r m s}\left(P_{\text {out }}, d\right)$, $\mathrm{SAR}_{\mathrm{wb}}\left(\mathrm{P}_{\text {out }}, \mathrm{d}\right)$ and $\mathrm{SAR}_{10 \mathrm{~g}}\left(\mathrm{P}_{\text {out }}, \mathrm{d}\right)$ (where $\mathrm{d}$ is distance) in every direction. The maximal $\mathrm{P}_{\text {out }}$ under realistic operating conditions are frequency dependent and are listed in Table 1. 


\section{Compliance boundaries}

The reference levels for the electric fields and the basic restrictions for $\mathrm{SAR}_{\mathrm{wb}}$ and $\mathrm{SAR}_{10 \mathrm{~g}}$ (for the general public and occupational exposure) defined by ICNIRP [ICNIRP, 1998] are used to determine compliance boundaries for the BSAs.

Compliance distances $d_{\text {compl }}^{S A R_{x}}(f, P)$ are defined as the distance from the antenna where for a certain power $\mathrm{P}$ and frequency $\mathrm{f}$, the $\mathrm{SAR}_{\mathrm{x}}(\mathrm{x}=$ wb or $10 \mathrm{~g})$ values equal the basic restrictions. A similar compliance distance can also be defined by comparing $\mathrm{E}_{\mathrm{rms}}$ averaged over a volume (the BB of the VFM, with dimensions: 282 × 540 x $1804 \mathrm{~mm}^{3}$ ) with the reference levels: $d_{\text {compl }}^{E}(f, P)$. Although other publications use a surface [Lacroux et al., 2008] to calculate compliance boundaries based on the reference levels, we have chosen to average $\mathrm{E}_{\mathrm{rms}}$ over a volume surrounding the VFM, because the reference levels should be averaged over the entire body [ICNIRP, 1998].

The antennas under consideration emit at multiple frequencies simultaneously. Table 1 shows the typical maximal operational output powers per frequency for each antenna. The maximum powers range from 120 to $300 \mathrm{~W}$. Since the antennas radiate electric fields at multiple frequencies, comparison of the fields and SAR values at an individual frequency with the ICNIRP basic restrictions and reference levels at that frequency does not suffice. To check compliance with the basic restrictions and reference levels, one has to use following formulas [ICNIRP, 1998]:

$$
\begin{aligned}
& \sum_{i=1}^{4}\left(\frac{E_{i}^{2}}{E_{\text {ref }}^{2}}\right) \leq 1 \\
& \sum_{i=1}^{4} \frac{S A R_{i}}{S A R_{B R}} \leq 1
\end{aligned}
$$


Where the index $i$ denotes the 4 different frequencies. $E_{\text {ref }}$ and $\mathrm{SAR}_{\mathrm{BR}}$ are the ICNIRP reference levels and basic restrictions, respectively. $\mathrm{SAR}_{\mathrm{i}}$ can be either whole-body averaged SAR or peakspatial $10 \mathrm{~g}$ averaged SAR. To check compliance with the basic restrictions for the peak $\mathrm{SAR}_{10 \mathrm{~g}}$, equation (2) should be fulfilled in every grid cell of the human body phantom. It is a computationally heavy task to control this. We use a worst-case approximation valid for all cases, in accordance with the ICNIRP guidelines [ICNIRP, 1998] which are used to determined compliance boundaries in this study, where all the maximal $10 \mathrm{~g}$ SARs at different frequencies are assumed to be located at the same point in the body. Therefore we use equation (3):

$$
\sum_{i=1}^{4} \frac{S A R_{10 g, p e a k, i}}{S A R_{B R, 10 g}} \leq 1
$$

This will provide a conservative estimation of the cumulative peak $\mathrm{SAR}_{10 \mathrm{~g}}$ according to ICNIRP [ICNIRP, 1998]. Using equations (1), (2) and (3), compliance boundaries $d_{c o m p l}^{S A R_{x}}\left(P_{f_{1}}, P_{f_{2}}, P_{f_{3}}, P_{f_{4}}\right)$ and $d_{c o m p l}^{E}\left(P_{f_{1}}, P_{f_{2}}, P_{f_{3}}, P_{f_{4}}\right)$ can be estimated. The final compliance distance will be determined by the maximum of all the different compliance distances. Equivalently, maximally allowed powers $P_{\text {compl }}^{E}(d)$ and $P_{\text {compl }}{ }^{E A R_{x}}(d)$, which are the powers needed to obtain the basic restrictions or reference levels at a certain distance from the antenna, can be determined, both for individual frequencies and cumulative exposure.

\section{RESULTS}

In order to determine compliance distances, $\mathrm{E}_{\mathrm{rms}}, \mathrm{SAR}_{\mathrm{wb}}$ and $\mathrm{SAR}_{10 \mathrm{~g}}$ are determined in front of, at the side and at the back of the three studied BSAs. First, the compliance boundaries and the allowed powers for the individual frequencies are studied. Secondly, cumulative or multiplefrequency exposure is considered. This section concludes with an estimation of the errors at large 
separations between the antenna and the VFM and an uncertainty analysis of the obtained compliance distances.

\section{Compliance boundaries based on $S A R_{w b}$ and peak $S A R_{10 g}$}

Compliance distances can be determined based on the whole-body and peak-spatial averaged specific absorption rate (SAR). These have to be verified using the ICNIRP basic restrictions. The basic restrictions for the general public in the frequency range of $10 \mathrm{MHz}-10 \mathrm{GHz}$ are $0.08 \mathrm{~W} / \mathrm{kg}$ for $\mathrm{SAR}_{\mathrm{wb}}, 2 \mathrm{~W} / \mathrm{kg}$ for $\mathrm{SAR}_{10 \mathrm{~g} \text {,trunk }}$ and $4 \mathrm{~W} / \mathrm{kg}$ for $\mathrm{SAR}_{10 \mathrm{~g}, \text { limbs }}$ [ICNIRP, 1998]. The basic restrictions for occupational exposure are a factor 5 higher.

In order to show how compliance boundaries are determined a case study of compliance distances based on $\mathrm{SAR}_{\mathrm{wb}}$ for antenna 1 is shown in Figure 3.

\section{Determination of compliance boundaries}

Figure 3 illustrates how compliance boundaries are determined, using an example in front of antenna 1, where $30 \mathrm{~W}$ is emitted at 800 and $900 \mathrm{MHz}$ and $70 \mathrm{~W}$ is emitted at 1800 and $2600 \mathrm{MHz}$. Figure 3 shows that at short distances (for example distances smaller than $560 \mathrm{~mm}$ for $30 \mathrm{~W}$ at 800 and $900 \mathrm{MHz}$ ) from the antenna, the ICNIRP basic restrictions for the general public are not satisfied. With increasing separation, $\mathrm{SAR}_{\mathrm{wb}}$ decreases and finally becomes smaller than the basic restriction for the general public. If radiation would only be present at the single frequencies, the compliance distances for $\mathrm{SAR}_{\mathrm{wb}}$ would be located where the blue, black, green and pink curves intersect with the horizontal dashed lines, e.g., $560 \mathrm{~mm}$ for $30 \mathrm{~W}$ at $800 \mathrm{MHz}, 610 \mathrm{~mm}$ for $30 \mathrm{~W}$ at $900 \mathrm{MHz}, 1280 \mathrm{~mm}$ for $70 \mathrm{~W}$ at $1800 \mathrm{MHz}$ and $1420 \mathrm{~mm}$ for $70 \mathrm{~W}$ at $2600 \mathrm{MHz}$ for the general public. In these points the $\mathrm{SAR}_{\mathrm{wb}}$ will equal the basic restriction at these frequencies. The red curve in Figure 3 ("all frequencies") shows the 
summation of the different $\mathrm{SAR}_{\mathrm{wb}}$ as a function of distance from the antenna 1 . Where this curve intersects with the horizontal dashed black line, the actual compliance distance for these output powers can be found, i.e., $4010 \mathrm{~mm}$ for the general public and $860 \mathrm{~mm}$ for occupational exposure. Also note that for 800 and $900 \mathrm{MHz}$ at $30 \mathrm{~W}$ no individual compliance boundaries exist for occupational exposure (because the basic restrictions are not exceeded), but due to the cumulative exposure a compliance distance does exist. For other output powers the curves can be rescaled.

\section{Compliance boundaries based on the basic restrictions on $\mathrm{SAR}_{\mathrm{wb}}$ and peak $\mathrm{SAR}_{\mathbf{1 0 g}}$}

Figure 4 shows the maximally allowed output power the three antennas can emit frontally in order to induce SAR values in the VFM human body model equal to the ICNIRP basic restriction for general public (left axis) and occupational exposure (right axis). The allowed powers and compliance distances in front of the three antennas based on the different averaged SAR values are shown. For instance, for antenna 1 at $800 \mathrm{MHz}$, the ICNIRP basic restriction for $\mathrm{SAR}_{\mathrm{wb}}$ and the general public is exceeded at a distance of $2 \mathrm{~m}$ in front of the antenna for output powers larger than $91.2 \mathrm{~W}$ (Fig. 4a). We have chosen not to show the compliance boundaries at the side and back of the antennas for the individual frequencies.

At close distances in front of the antenna, the localized $\mathrm{SAR}_{10 \mathrm{~g}}$ induced in the trunk and head of the human body is more restrictive than the $\mathrm{SAR}_{\mathrm{wb}}$ and thus determines the compliance distance, as is shown in Figure 4. This holds for all frequencies and antennas and can be seen by investigating Figure 4 at a constant allowed output power and determining the curve that provides the highest safety distance, e.g., at $800 \mathrm{MHz}$ and $31.6 \mathrm{~W}$ of output power: the compliance distances for the general public based on $\mathrm{SAR}_{\mathrm{wb}}$ are 610,560 and $350 \mathrm{~mm}$ for antenna 1 to 3 
respectively, while based on $\mathrm{SAR}_{10 \mathrm{~g} \text {,trunk }}$ these are 850,680 and $850 \mathrm{~mm}$. At higher distances the $\mathrm{SAR}_{\mathrm{wb}}$ or $\mathrm{SAR}_{10 \mathrm{~g}, \mathrm{limbs}}$ can become the most stringent basic restriction.

The results presented in this paper show an excellent agreement with the ones presented in Thors et al. [2008]. The values for compliance boundaries based on $\mathrm{SAR}_{\mathrm{wb}}$ and $\mathrm{SAR}_{10 \mathrm{~g}}$ presented in that paper, for the VFM near an antenna emitting at $900 \mathrm{MHz}$ with a horizontal beam width of $70^{\circ}$ a vertical beam width of $12^{\circ}$, a length of $1.3 \mathrm{~m}$ and a gain of $14 \mathrm{dBi}$, are within the error margin of the results shown in Figure 4 (b). The values presented in Cooper et al. [2002] for a base station of length $1.14 \mathrm{~m}$ consisting of an array of 4 dipoles emitting at $935 \mathrm{MHz}$ and simulations using the visible human correspond well with the values in Figure 4 (b) for occupational exposure, i.e., at $350 \mathrm{~mm}$ [Cooper et al., 2002] determined an allowed power of $100 \mathrm{~W}$, while for the 3 antennas in this study this is $155 \mathrm{~W}, 135 \mathrm{~W}$ and $115 \mathrm{~W}$. The $10 \mathrm{~g}$ averaged SAR values presented in Joseph et al. [2005] for a base station antenna with a gain of $15.5 \mathrm{dBi}$, a horizontal beam width of $90^{\circ}$, a vertical beam width of $8.5^{\circ}$ and a length of $1.9 \mathrm{~m}$, that emits at $947.5 \mathrm{MHz}$, increases up to an allowed power of $27.5 \mathrm{~W}$ at $60 \mathrm{~mm}$; this is situated in the range of our values for the $\mathrm{SAR}_{10 \mathrm{~g}, \text { trunk }}$ at $60 \mathrm{~mm}: 20.4 \mathrm{~W}, 135 \mathrm{~W}$ and $38 \mathrm{~W}$ at $900 \mathrm{MHz}$ for the three considered antennas, which is to be expected as the phantom used in the study [Joseph et al., 2005] emulates the trunk of a human body.

\section{Compliance boundaries based on the electric field}

The reference levels on the electric fields, defined by ICNIRP, are also used to define compliance

boundaries. They are $1.375 f^{\frac{1}{2}}(\mathrm{~V} / \mathrm{m})$ for the general public and $3 f^{\frac{1}{2}}$ for occupational exposure for 400-2000 MHz and $61 \mathrm{~V} / \mathrm{m}$ for the general public and $137 \mathrm{~V} / \mathrm{m}$ for occupational exposure for 2-300 GHz [ICNIRP, 1998]. Figure 5 shows the allowed power of the antennas (front, side and 
back) in order to comply with the reference levels for the general public (left axis) and occupational exposure (right axis), averaged over the BB surrounding the phantom at a certain distance from the antenna. The corresponding compliance distances can be determined for any realistic output power using this figure. For example, at an operating frequency of $800 \mathrm{MHz}$, the ICNIRP reference level for the general public is exceeded at a distance of $1.5 \mathrm{~m}$ in front of antenna 2 for input powers larger than $31.6 \mathrm{~W}$ (Fig. 5 a). The three antennas show the same behaviour. Clearly, the highest safety distances are obtained in front of the antennas, as the antennas' main lobes are in this direction.

The allowed powers can be compared to the maximal operational output powers listed in Table 1 . At 1800 and $2600 \mathrm{MHz}$ (Fig. $5 \mathrm{c}$ and d) no compliance distances based on the electric field will exist for the general public at the side and back of the antenna, since the power that is necessary to obtain $E_{\text {rms }}$ fields equal to the reference levels is higher than the maximal operational power (see Table 1). At 800 and $900 \mathrm{MHz}$, compliance boundaries for the general public also exist at the side and back of the antennas for high operational powers. For occupational exposure compliance distances only exist in front of the antenna for these allowed output powers.

At the largest distance $(200 \mathrm{~mm})$ considered in Joseph et al. [2005] the results for the compliance distances for occupational exposure based on the electric field in front of their BSA (with a gain of $15.5 \mathrm{dBi}$, a horizontal beam width of $90^{\circ}$, a vertical beam width of $8.5^{\circ}$ and a length of $1.9 \mathrm{~m}$ ) emitting at 947.5 MHz are comparable (differences smaller than a factor of 2) to the ones that are presented in this study. At closer distances to the antennas the values in Joseph et al. [2005] are more conservative. 


\section{Actual compliance boundaries based on SAR values and $E_{r m s}$}

The actual compliance distances are combined compliance distances where all quantities - the reference levels and basic restrictions - are met at a single frequency, based on the ICNIRP guidelines for the three antennas. In terms of the allowed powers this is calculated as $\min _{x}\left(P_{c o m p l}^{x}\left(f_{i}, d\right)\right)$, where $\mathrm{x}$ can be $\mathrm{E}_{\mathrm{rms}}, \mathrm{SAR}_{\mathrm{wb}}, \mathrm{SAR}_{10 \mathrm{~g}, \text { trunk }}$ or $\mathrm{SAR}_{10 \mathrm{~g}, \text { limbs. The actual }}$ compliance distances for the general public and occupational exposure should be determined separately, since the ratios between the reference levels and the basic restrictions are not the same and are frequency dependent. For 800,900 , and $1800 \mathrm{MHz}$, the ratio of the allowed powers based on the reference levels for occupational exposure and the general public is 4.8 , while at $2600 \mathrm{MHz}$ this is 5.04. For the basic restrictions the ratio is exactly 5 at all considered frequencies.

Figure 6 shows the actual compliance distances and allowed powers for the three antennas, based on the ICNIRP guidelines for occupational exposure. This figure displays the minimal allowed power at each distance from the antenna. The green dashed lines show the maximal operational output powers from Table 1. We have chosen to show the allowed powers for occupational exposure, the allowed powers for the general public will be a factor of 5 lower, where a deviation of $4 \%$ is possible at the lower three frequencies, if the reference levels are the most restrictive quantity at a certain distance d. From Figure 6, it should be clear that restrictions on the output power exist in front of the antennas for occupational exposure using the operating powers given in Table 1. At the side and back of the antenna, restrictions only exist at $900 \mathrm{MHz}$, where an output power of $300 \mathrm{~W}$ induces a compliance distance of $5 \mathrm{~cm}$ at the side of antennas 1 and 2 and around $10 \mathrm{~cm}$ at the back of antennas 1 and 2. An RF worker can approach the BSAs in compliance with the ICNIRP reference levels and basic restrictions if an output power smaller than $158 \mathrm{~W}$ is 
emitted at one of the studied frequencies. A cumulative compliance distance is needed to study multiple-frequency exposure situations.

The results that are presented in Cecil et al. [2011] for the lowest allowed powers for BSAs with a horizontal beam width $>60^{\circ}$ based on any basic restriction for occupational exposure, are comparable to the worst case results for the combined compliance distances in Figure 6.

\section{Cumulative compliance distances}

In reality the BSAs will emit at multiple frequencies $f_{i}$ with output powers $P_{f_{i}}$. A cumulative compliance distance can be determined for every combination of output powers $P_{f_{i}}$, distance d from the antenna and basic restriction or reference level. The cumulative compliance distances and corresponding allowed powers can be calculated from the allowed powers presented in the previous sections using:

$$
\sum_{i=1}^{4} \frac{P_{f_{i}}}{P_{c o m p l}^{x}\left(f_{i}, d\right)}<1
$$

with $P_{c o m p l}^{x}\left(f_{i}, d\right)$ the allowed power which complies with the basic restrictions $\left(\mathrm{x}=\mathrm{SAR}_{\mathrm{wb}}\right.$ or $\left.\mathrm{SAR}_{10 \mathrm{~g}}\right)$ or reference levels $\left(\mathrm{x}=\mathrm{E}_{\mathrm{rms}}\right)$ at frequency $\mathrm{f}_{\mathrm{i}}$ and distance $\mathrm{d}$ from the antenna. $P_{f_{i}}$ is the output power at frequency $\mathrm{f}_{\mathrm{i}}$. This can be calculated for both the general public and occupational exposure and any set of output powers $P_{f_{i}}$. The exact compliance distance for a specific power distribution can be calculated by inserting the output powers $P_{f_{i}}$ and the combined allowed powers $P_{\text {compl }}^{x}\left(f_{i}, d\right)$ from Figures 4 and 5 in equation (4).

A total output power of $P=\sum_{i=1}^{4} P_{f_{i}}$ can be obtained using different combinations of $P_{f_{i}}$ and will thus also lead to a different compliance distance. Since a compliance boundary should be a 
constant distance for a given output power, the largest distances that can be found for a total output power $\mathrm{P}$ have been determined. Equivalently, one can estimate the lowest $\mathrm{P}$ at a given distance, which complies with the basic restrictions and reference levels at all frequencies, regardless the distribution of the powers amongst the frequencies. It is this $\mathrm{P}$ that is shown in Figure 7.

Figure 7 thus shows the worst-case cumulative compliance distances for the general public based on the individual basic restrictions (red, blue and green markers) for the three studied antennas at the points where an FDTD simulation has been carried out. The markers show the values obtained from numerical simulations. The solid lines are fitted lines to the compliance distances for the individual basic restrictions and reference levels. An exponential fit for the power as a function of the compliance distance is applied:

$$
P(W)=A \times\left(\frac{d(m m)}{1 m m}+C\right)^{B}
$$

With $\mathrm{A}, \mathrm{B}$ and $\mathrm{C}$ the parameters of the fit and $\mathrm{d}$ the cumulative compliance distance. The fit is carried out for distances larger than a quarter wavelength. Table 2 summarizes the values for A, $\mathrm{B}$, and $\mathrm{C}$ for the 3 antennas. Figure 7 shows that at distances close to the antennas $(<1 \mathrm{~m})$, the basic restrictions for $\mathrm{SAR}_{10 \mathrm{~g}, \text { trunk }}$ will be the most conservative, while at larger distances from the antenna, the reference levels can be the most conservative.

The allowed power presented in Figure 7 can be extended to the worst-case scenario for occupational exposure if the allowed power is multiplied by a factor of 5 . The aforementioned deviation of $4 \%$ due to a difference in ratio between reference levels and basic restrictions has to be taken into account. From Figure 7, one can conclude that antennas 1, 2, and 3 can be 
approached up till $0.1 \mathrm{~m}$ from the back and side by an informed RF worker, if the total output power is smaller than $316 \mathrm{~W}, 398 \mathrm{~W}$, and $1 \mathrm{~kW}$, respectively.

\section{Simulation errors at large ( $>2 \mathrm{~m}$ ) distances from the antenna}

FDTD discretizes the full simulation domain and calculation times can thus become too long at large distances from the antenna. To investigate compliance with the basic restrictions at these distances we have used the Generalized Huygens' Box Method [Vermeeren et al., 2010] and an extrapolation of the simulation results at even larger distances.

\section{Error due to the use of the Generalized Huygens' Box Method}

The GHBM is used for separations between the VFM and the BSAs larger than $2 \mathrm{~m}$. The validity of this method has been tested at the four studied frequencies, using the VFM placed at $2 \mathrm{~m}$ from antenna 1. The $\mathrm{SAR}_{\mathrm{wb}}$ and peak $\mathrm{SAR}_{10 \mathrm{~g}}$ values obtained using the GHBM deviate $8.9 \%$ and $9.3 \%$ on average from the values obtained using FDTD simulations. The error is smaller at larger distances from the BSA, as the antenna-phantom coupling decreases.

\section{Extrapolation error on allowed powers at large distances from the antennas}

As can be seen in Figure 3, the cumulative compliance boundaries can be quite larger than the compliance boundaries for the individual frequencies. In order to limit the number of far-field simulations, an extrapolation is used at larger distances.

To determine the different SAR values at the back orientation, we extrapolate beyond $30 \mathrm{~cm}$. This gives rise to an average error of $12 \%$ at $50 \mathrm{~cm}$. The extrapolation for the SAR values at the face of the antenna (beyond $5 \mathrm{~m}$ ) is checked for antenna 2 at $10 \mathrm{~m}$ with an average error of $40 \%$. These 
errors are acceptable when compared to the worst-case correlated error associated with FDTD with heterogeneous human body models (i.e., order of 64\% [Bakker et al., 2010]).

For the E-field values, we also use an extrapolation beyond $500 \mathrm{~cm}$ in front of the antennas, this is checked for antenna 3 at $1000 \mathrm{~cm}$ and gives rise to an average error of $15 \%$. At the side and back of the antennas we extrapolated the electric fields beyond $50 \mathrm{~cm}$, this is associated with an average error of $35 \%$ at $100 \mathrm{~cm}$.

\section{Uncertainty analysis}

Every measurement or numerical computation induces uncertainties on the obtained results. These are discussed in this section.

\section{Uncertainty on the Allowed Power}

The results for the allowed power: $P_{c o m p l} \operatorname{SAR}_{x}(d)(\mathrm{x}=$ wb or $10 \mathrm{~g})$, are directly calculated from

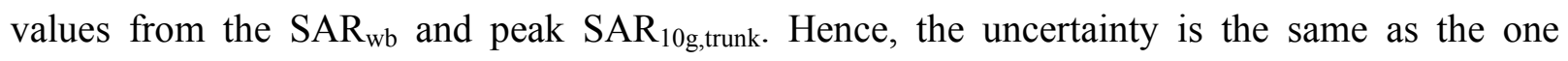
already investigated in previous studies [Findlay et al., 2006; Kühn et al., 2009; Bakker et al., 2010; Vermeeren et al., 2010]. Because the selected FDTD settings are similar and for some parameters even better than in the referenced papers, the estimated uncertainty is not larger than the overall uncertainty presented in these studies. The overall worst-case expanded uncertainty U $(\mathrm{k}=2)$ with $95 \%$ confidence interval is $59 \%$ and $64 \%$ for $\mathrm{SAR}_{\mathrm{wb}}$ and $\mathrm{SAR}_{10 \mathrm{~g}}$, respectively and will be the same for allowed powers associated with these SAR values [Bakker et al., 2010].

\section{Uncertainty on the compliance distance}

The uncertainties on $\mathrm{SAR}_{\mathrm{wb}}$ and $\mathrm{SAR}_{10 \mathrm{~g}}$ [Bakker et al., 2010] can be used to determine uncertainties on the compliance distances. The performed FDTD computations provide 
relationships $\mathrm{SAR}_{\mathrm{wb}}(\mathrm{d})$ and $\mathrm{SAR}_{10 \mathrm{~g}}(\mathrm{~d})$, such as the ones shown in Figure 8. The distance $\mathrm{d}$ at which the SAR value is equal to $\mathrm{SAR}_{\mathrm{BR}}$ is the compliance distance. Upper and lower boundaries for the $95 \%$ confidence interval on the SAR can be determined, using the expanded uncertainty on the SAR values. The distances $d_{1}$ and $d_{2}$ where these lower and upper boundaries equal the basic restrictions can be determined using equations (6) and (7):

$$
\begin{aligned}
& S A R_{x}\left(d_{1}\right)-S A R_{x}\left(d_{1}\right) \times U=S A R_{B R} \\
& S A R_{x}\left(d_{2}\right)+S A R_{x}\left(d_{2}\right) \times U=S A R_{B R}
\end{aligned}
$$

where $\mathrm{x}=\mathrm{wb}$ or $10 \mathrm{~g}$. The interval $\left[d_{1}, d_{2}\right]$ corresponds to the $95 \%$ confidence interval for the compliance distance. Figure 8 shows the simulated $\mathrm{SAR}_{\mathrm{wb}}(\mathrm{d})$ and $\mathrm{SAR}_{10 \mathrm{~g}, \text { trunk }}(\mathrm{d})$ for antenna 1 at $800 \mathrm{MHz}$, for an antenna input power of $120 \mathrm{~W}$. The distances $\mathrm{d}_{1}, \mathrm{~d}_{2}$, and $95 \%$ confidence intervals are indicated in this figure. The dashed curves show the upper and lower limits of the $95 \%$ confidence intervals. The red lines are the respective basic restrictions on $\mathrm{SAR}_{\mathrm{wb}}(0.08$ $\mathrm{W} / \mathrm{kg})$ and $\mathrm{SAR}_{10 \mathrm{~g}, \text { trunk }}(2 \mathrm{~W} / \mathrm{kg})$ for the general public. The confidence interval for the compliance distances can be found where the red lines intersect with the dashed curves. In the example of Figure 8: $\mathrm{d}=2570 \mathrm{~mm}$, while $\mathrm{d}_{1}=1210 \mathrm{~mm}$ and $\mathrm{d}_{2}=3770 \mathrm{~mm}$ for $\mathrm{SAR}_{\mathrm{wb}}=0.08 \mathrm{~W} / \mathrm{kg}$.

To estimate a power averaged uncertainty of the compliance distances, one has to determine the relationships $d_{\text {safety }}\left(P_{\text {in }}\right), d_{1}\left(P_{\text {in }}\right)$ and $d_{2}\left(P_{\text {in }}\right)$. The average relative upper ( $\left.\operatorname{err}_{\text {up }}\right)$ and lower boundaries $\left(\mathrm{err}_{\text {low }}\right)$ of the $95 \%$ confidence interval can be determined by calculating following integrals:

$$
\operatorname{err}_{u p}(f)=\frac{1}{P_{\max }(f)-P_{\min }(f)} \int_{P_{\min }(f)}^{P_{\max }(f)}\left(d_{2}(P)-d(P)\right) / d(P) d P
$$




$$
\operatorname{err}_{\text {low }}(f)=\frac{1}{P_{\max }(f)-P_{\min }(f)} \int_{P_{\min }(f)}^{P_{\max }(f)}\left(d(P)-d_{1}(P)\right) / d(P) d P
$$

With $P_{\min }(f)$ and $P_{\max }(f)$ the minimum and maximum input powers taken from Table 1 . Table 3 summarizes the power averaged relative errors that determine the $95 \%$ confidence interval for the individual frequencies in front of the antenna. The errors range from $56-122 \%$ for the $\mathrm{SAR}_{\mathrm{wb}}$ and

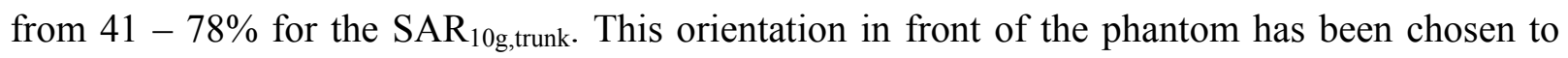
estimate the errors, because it has the most non-zero values for the compliance distances. The

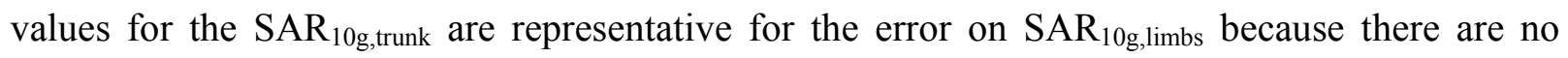
differences in the calculation methods.

\section{DISCUSSION}

This study numerically investigates compliance boundaries based on the ICNIRP basic restrictions and reference levels, using the VFM. The obtained compliance boundaries and allowed powers are presented in the previous section. The discussion section consist out of three parts: first the differences between $\mathrm{SAR}_{\mathrm{wb}}$, the peak $\mathrm{SAR}_{10 \mathrm{~g}}$ and $\mathrm{E}_{\mathrm{rms}}$ are discussed, secondly the conservativeness of the ICNIRP reference levels is investigated, and finally the cumulative compliance distances are treated.

Figure 5 shows that the curves based on $E_{\text {rms }}$ generally follow the same trend for the three antennas. The same holds for the $\mathrm{SAR}_{\mathrm{wb}}$, see Figure 4. Due to the whole-body averaging $\left(\mathrm{SAR}_{\mathrm{wb}}\right)$ and the averaging over a volume surrounding the phantom $\left(\mathrm{E}_{\mathrm{rms}}\right)$, differences in antenna design

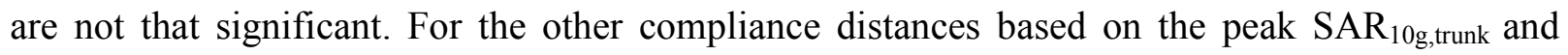
$\mathrm{SAR}_{10 \mathrm{~g}, \mathrm{limbs}}$ more variation exists in the position and value of the maxima as the phantom moves 
away from the antenna. The location and value of the peak $\mathrm{SAR}_{10 \mathrm{~g}}$ are dependent on the exposure conditions and on the heterogeneity and shape of the used phantom. The differences in value of the peak $10 \mathrm{~g}$ averaged SAR for the different antennas at the same phantom positions are due to differences in antenna design, length and number of radiating antennas at a certain frequency (see Table 1), which can cause other locations and values of the peak $\mathrm{SAR}_{10 \mathrm{~g}}$ in the VFM.

The reference levels for the electric fields are deduced from the basic restrictions on whole body averaged SAR for plane-wave exposure (far field) of a spheroid phantom [ICNIRP, 1998]. The reference levels ought to be more conservative, meaning that the reference levels could be exceeded while the basic restrictions are not exceeded. This is not always the case for a heterogeneous human in the near field of a BSA.

In this study we used a realistic human body phantom which is exposed to a BSA. When comparing Figures 4 and 5 one can see that the reference levels are not always conservative, i.e., sometimes $P_{c o m p l}^{E_{r m s}}(f, d)>P_{c o m p l}^{S A R_{w b}}(f, d)$. For the lower frequencies 800 and $900 \mathrm{MHz} P_{c o m p l}^{E_{r m s}}(f, d)$ is always smaller than $P_{c o m p l}^{S A R}(f, d)$, while for the higher frequencies 1800 and $2600 \mathrm{MHz}$, this is not always true. We attribute this to both the localized nature of the exposure and the quadratic relationship between incident power and electric fields. At the lower frequencies (800 and $900 \mathrm{MHz})$ the full antenna is emitting, while at the higher frequencies (1800 and $2600 \mathrm{MHz})$ only one half of the antenna is emitting. Since the $E_{\mathrm{rms}}$ is calculated as a volume average, the spatial distribution of the electric fields will play a role. Areas in the volume with a lower coverage by the antenna will lower the overall average $\mathrm{E}_{\mathrm{rms}}$ field and thus increase the power needed to obtain the reference levels. The number of patch antennas will also influence the $\mathrm{SAR}_{\mathrm{wb}}$ values, since a heterogeneous phantom is used. To investigate this we have performed simulations where antenna 
1 is adapted to have 11 patch antennas emitting at $2600 \mathrm{MHz}$ spread over the full length of the antenna, instead of 5 over half the length of the antenna as in the original antenna 1 . Table 4 lists the differences in allowed powers at $2600 \mathrm{MHz}$ for the same antenna with different numbers of radiating patch antennas. The table shows that when all 11 patch antennas are emitting, the allowed power based on the electric fields is indeed more conservative than the one based on $\mathrm{SAR}_{\mathrm{wb}}$. While when only 5 patch antennas are emitting the reference levels allow for higher powers.

To gain more insight in the curves $P_{c o m p l}^{a l l}(P, d)$ a fit using equation (5) was carried out. A linear decay of the SAR values due to the cylindrical nature of wave propagation is expected in the region close to a linear array of antennas, while further away from the antenna a spherical propagation is expected, leading to a quadratic decay of SAR values with distance [Cicchetti et al., 2004; Thors et al., 2008; Gosselin et al., 2011]. The different simulation results used to determine the cumulative compliance distance are situated in both the region of cylindrical propagation and the spherical propagation region, depending on the frequency and distance from the antenna [Thors et al., 2008]. An average value of $1.4 \pm 0.5$ was estimated for B, as shown in Table 2, which implies an increase of the allowed power with $d^{1.4 \pm 0.5}$ confirming the interplay between cylindrical and spherical propagation.

\section{CONCLUSIONS}

We investigated numerically the compliance boundaries based on the $\mathrm{SAR}_{\mathrm{wb}}$, peak $\mathrm{SAR}_{10 \mathrm{~g}}$ in head and trunk or in the limbs, and on the $\mathrm{E}_{\mathrm{rms}}$ using the ICNIRP basic restrictions and reference levels for the general public and occupational exposure. Both compliance distances and allowed powers were determined in three directions from three base station antennas that emit at four 
frequencies. Realistic maximal output powers were chosen for the antennas. The results based on different basic restrictions and reference levels are compared and a combined compliance distance, at which all basic restrictions and reference levels are met, is determined for every frequency. We observed that the ICNIRP reference levels are not always conservative and that electric field measurements or simulations only are insufficient to obtain the actual compliance boundary. A cumulative compliance distance, in the case that all the frequencies are emitted simultaneously, was defined. At short distances $(<1000 \mathrm{~mm})$ the cumulative compliance

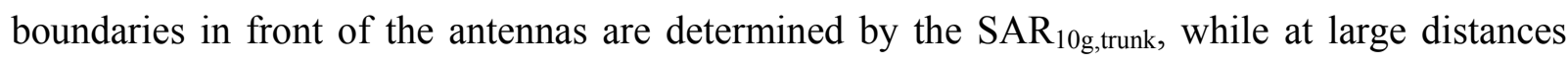
other quantities can become more conservative. At the side and back of the antennas cumulative compliance distances only exist at short distances from the antenna $(<1000 \mathrm{~mm})$ for realistic output powers ranging up to $300 \mathrm{~W}$ per frequency. Compliance with all basic restrictions is guaranteed for the studied antennas up till $10 \mathrm{~cm}$ at the back and side, if the total emitted output power is lower than $316 \mathrm{~W}$ independent from the power distribution over the different frequencies. The relative errors on the compliance distances were also determined $(<122 \%)$. The obtained results could be expanded with simulations using different models of phantoms and antennas. We are also looking into using surrogate modeling as a tool to determine allowed powers in a $2 \mathrm{D}$ plane or $3 \mathrm{D}$ environment surrounding the antenna.

\section{ACKNOWLEDGEMENTS}

W. Joseph is a Post-Doctoral Fellow of the FWO-V (Research Foundation - Flanders). 


\section{REFERENCES}

3rd Generation Partnership Project (3GPP). 2009. LTE; 3rd Generation Partnership Project; Technical Specification Group Radio Access Network; Evolved Universal Terrestrial Radio Access (E-UTRA); User Equipment (UE) Radio Transmission and Reception (TS 36.101 v9.1.0 Release 9). Sophia-Antipolis Cedex, France.

Bakker J F, Paulides M M, Christ A, Kuster N, van Rhoon GC. 2010. Assessment of induced SAR in children exposed to electromagnetic plane waves between $10 \mathrm{MHz}$ and 5.6 GHz. Phys Med Biol 55(11): 3115-3130.

Bernardi P, Cavagnaro M, Pisa S, Piuzzi E. 2000 Human exposure to radio base-station antennas in urban environment. IEEE Trans Microw Theory Tech 48: 1996-2002.

Cecil S, Martin K, Escorihuela-Navarro A, Friedrich G, Neubauer G. June 2010. Safety Distance Concept for LTE-Frequencies. Poster at the $32^{\text {nd }}$ Annu Meeting of the Bioelectromagnetics Society (BEMS 2011) (Halifax Canada, June 2011).

Christ A, Kainz W, Hahn E G, Honegger K, Zefferer M, Neufeld E, Rascher W, Janka R, Bautz W, Chen J, Kiefer B, Schmitt P, Hollenbach H, Shen J, Oberle M, Szczerba D, Kam A, Guag J W, Kuster N. 2010. The Virtual Family, development of surface-based anatomical models of two adults and two children for dosimetric simulations. Phys Med Biol 55: N23-38.

Cicchetti R, Faraone A. 2004. Estimation of the Peak Power Density in the Vicinity 
of Cellular and Radio Base Station Antennas. IEEE Trans on Electromagnetic Compatibility 46(2): $275-290$.

Cooper J, Marx B, Buhl J, Hombach V. 2002. Determination of safety distance limits for a human near a cellular base station antenna, adopting the IEEE standard or ICNIRP guidelines. Bioelectromagnetics 23: 429-443.

Findlay RP, Dimbylow PJ. 2006. Variations in calculated SAR with distance to the perfectly matched layer boundary for a human voxel model. Phys Med Biol 51(23): N411-5.

Gabriel C, Gabriel S, Corthout E. 1996. The dielectric properties of biological tissues. Phys Med Biol 41: 2231-2293.

Gosselin MC, Christ A, Kühn S, Kuster N. 2009. Dependence of the Occupational Exposure to Mobile Phone Base Stations on the Properties of the Antenna and the Human Body. IEEE Trans on Electromagnetic Compatibility 51(2): 227-235.

Gosselin MC, Vermeeren G, Kühn S, Kellerman V, Benkler S, Uusitupa TMI, Joseph W, Gati A, Wiart J, Meyer FJC, Martens L, Nojima T, Hikage T, Balzano Q, Christ A, Kuster N. 2011. Estimation Formulas for the Specific Absorption Rate in Humans Exposed to Base-Station Antennas. IEEE Trans on Electromagnetic Compatibility 53(4): 909-922. 
Hand J. 2008. Modelling the interaction of electromagnetic fields (10 MHz-10 GHz) with the human body: methods and applications. Phys Med Biol 53: 243-286.

ICNIRP. 1998. Guidelines for limiting exposure to time varying electric, magnetic, and electromagnetic field (up to $300 \mathrm{GHz}$ ). Health Phys 74: 494-522.

International Electrotechnical Commission (IEC). 2011. Determination of RF field strength and SAR in the vicinity of radiocommunication base stations for the purpose of evaluating human exposure. International Standard 62232. Geneva, Switzerland.

Joseph W, Martens L. Nov 2005. Comparison of safety distances based on the electromagnetic field and based on the SAR for occupational exposure of a 900-MHz base station antenna. IEEE Trans on Electromag Compat 47(4): 977-985.

Kühn S, Cabot E, Christ A, Capstick M, Kuster N. 2009. Assessment of induced radio-frequency electromagnetic fields in various anatomical human body models. Phys Med Biol 54(4): 875-890.

Lacroux F, Conil E, Carrasco A, Gati A, Wong MF, Wiart J. 2008. Specific absorption rate assessment near a base station antenna (2,140 MHz): some key points. Ann Telecommun, 63: 55-6.

Thors B, Strydom ML, Hansson B, Meyer FJC, Kärkkäinen K, Zollman P, Ilvonen S, Törneviv C. Nov. 2008. On the estimation of SAR and compliance distance related to RF exposure from 
mobile communication base station antennas. IEEE Trans on Electromag Compatibility 50(4): 837-848.

Vermeeren G, Gosselin MC, Kühn S, Kellerman V, Hadjem A, Gati A, Joseph W, Wiart J, Meyer F, Kuster N, Martens L. 2010. Influence of the reflective environment on the absorption of a human male exposed to representative base station antennas from $300 \mathrm{MHz}$ to $5 \mathrm{GHz}$. Phys Med Biol 55(18): 5541-5555. 


\section{List of captions}

Table 1: Characteristics and operating frequency and powers of the three studied antennas.

Table 2: Values for fit coefficients A, B and C in equation (5) for the three studied antennas and the different studied dosimetric quantities.

Table 3: Relative power averaged lower and upper errors for the compliance distances, as defined in equations (8) and (9), for the general public, in front of the antennas. The First column lists the different antennas and frequencies. The second and third column list $\operatorname{err}_{\text {low }}$ and $\operatorname{err}_{\text {up }}$ on the compliance distances based on $\mathrm{SAR}_{\mathrm{wb}}$ and peak $\mathrm{SAR}_{10 \mathrm{~g}}$, respectively.

Table 4: Allowed powers at $300 \mathrm{~mm}$ from antenna 1, when only the upper half of the antenna is radiating and when the full antenna is radiating.

Figure 1: Scheme of the virtual human family male (VFM) in the vicinity of a base station antenna (BSA), indicating the vertical alignment and distance between the VFM's bounding box (BB) and BSA. The position of the generalized Huygens Box (GHB) and the VFM's Bounding Box (BB) are also shown.

Figure 2: Top view illustrating the different possible orientations and horizontal alignment of the VFM compared to the BSA. The contour of the GHB is also shown.

Figure 3: $\mathrm{SAR}_{\mathrm{wb}}$ as a function of distance in front of antenna 1, for $30 \mathrm{~W}$ at 800 and $900 \mathrm{MHz}$ and $70 \mathrm{~W}$ at 1800 and $2600 \mathrm{MHz}$.

Figure 4: Compliance distances for the general public and occupational exposure in front of the three studied antennas at (a) $800 \mathrm{MHz}$, (b) $900 \mathrm{MHz}$, (c) $1800 \mathrm{MHz}$ and (d) $2600 \mathrm{MHz}$ based on 
the whole body and peak $10 \mathrm{~g}$ averaged SAR. The markers show the simulated values, while the lines show a spline interpolation.

Figure 5: Compliance distances for the general public and occupational exposure of the three studied antennas at (a) $800 \mathrm{MHz}$, (b) $900 \mathrm{MHz}$, (c) $1800 \mathrm{MHz}$ and (d) $2600 \mathrm{MHz}$ based on the root mean squared electric field. The markers show the simulated values, while the lines show a spline interpolation.

Figure 6: Actual compliance distances for the general public and occupational exposure for three orientations around the three studied antennas at (a) $800 \mathrm{MHz}$, (b) $900 \mathrm{MHz}$, (c) $1800 \mathrm{MHz}$ and (d) $2600 \mathrm{MHz}$.

Figure 7: Allowed total output power as a function of distance for the general public at three orientations around the three studied antennas for (a) antenna 1, (b) antenna 2, and (c) antenna 3. The solid lines show a fit to the data in front of the antennas.

Figure 8: $\mathrm{SAR}_{\mathrm{wb}}$ and $\mathrm{SAR}_{10 \mathrm{~g}, \text { trunk }}$, with the corresponding uncertainty intervals, as a function of distance from antennal at $800 \mathrm{MHz}$ for $120 \mathrm{~W}$ output power. The red lines indicate the ICNIRP

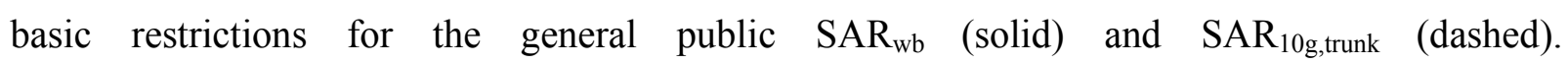




\begin{tabular}{|c|c|c|c|c|c|c|c|}
\hline Antenna & $\begin{array}{c}\text { Frequency } \\
\text { (MHz) }\end{array}$ & $\begin{array}{l}\text { Gain } \\
\text { (dBi) }\end{array}$ & $\begin{array}{c}\text { Horizontal } \\
\text { beam } \\
\text { width } \\
-3 \mathrm{~dB}\left({ }^{\circ}\right)\end{array}$ & $\begin{array}{l}\text { Vertical } \\
\text { beam } \\
\text { width } \\
-3 \mathrm{~dB}\left({ }^{\circ}\right)\end{array}$ & $\begin{array}{c}\text { Length } \\
\text { (m) }\end{array}$ & $\begin{array}{l}\text { Number of } \\
\text { radiating } \\
\text { patch } \\
\text { antennas }\end{array}$ & Power (W) \\
\hline \multirow{4}{*}{ Antenna 1} & 800 & 12.2 & 73 & 14.9 & \multirow{4}{*}{1.4} & 5 & 0 to 120 \\
\hline & 900 & 12.9 & 67 & 13.9 & & 5 & 0 to 300 \\
\hline & 1800 & 14.1 & 68 & 13.3 & & 3 & 0 to 240 \\
\hline & 2600 & 14.2 & 84 & 11.5 & & 6 & 0 to 120 \\
\hline \multirow{4}{*}{ Antenna 2} & 800 & 13.2 & 73 & 9.6 & \multirow{4}{*}{2.2} & 8 & 0 to 120 \\
\hline & 900 & 13.9 & 67 & 8.6 & & 8 & 0 to 300 \\
\hline & 1800 & 16.3 & 68 & 10.0 & & 4 & 0 to 240 \\
\hline & 2600 & 16.3 & 82 & 8.5 & & 8 & 0 to 120 \\
\hline \multirow{4}{*}{ Antenna 3} & 800 & 14.5 & 73 & 7.4 & \multirow{4}{*}{2.8} & 10 & 0 to 120 \\
\hline & 900 & 15.5 & 67 & 7.2 & & 10 & 0 to 300 \\
\hline & 1800 & 18.9 & 68 & 7.0 & & 5 & 0 to 240 \\
\hline & 2600 & 17.5 & 74 & 5.5 & & 12 & 0 to 120 \\
\hline
\end{tabular}

Table 1 


\begin{tabular}{|c|c|c|c|}
\hline Quantity & $\mathrm{A}(\mathrm{W})$ & $\mathrm{B}$ & $\mathrm{C}$ \\
\hline Antenna 1 & & & \\
\hline $\mathrm{E}_{\mathrm{RMS}}$ & $8.3 \times 10^{-4}$ & 1.4 & $7.3 \times 10^{2}$ \\
\hline $\mathrm{SAR}_{\mathrm{wb}}$ & $6.1 \times 10^{-3}$ & 1.2 & $3.2 \times 10^{2}$ \\
\hline $\mathrm{SAR}_{10 \mathrm{~g}, \mathrm{trunk}}$ & $4.4 \times 10^{2}$ & 1.3 & $8.9 \times 10^{1}$ \\
\hline $\mathrm{SAR}_{10 \mathrm{~g}, \mathrm{limbs}}$ & $8.4 \times 10^{-7}$ & 2.3 & $8.8 \times 10^{2}$ \\
\hline Antenna 2 & & & \\
\hline $\mathrm{E}_{\mathrm{RMS}}$ & $2.0 \times 10^{-2}$ & $9.8 \times 10^{-1}$ & $3.1 \times 10^{2}$ \\
\hline $\mathrm{SAR}_{\mathrm{wb}}$ & $1.7 \times 10^{-2}$ & 1.1 & $4.4 \times 10^{2}$ \\
\hline $\mathrm{SAR}_{10 \mathrm{~g}, \mathrm{trunk}}$ & $5.5 \times 10^{-2}$ & $8.6 \times 10^{-1}$ & $5.4 \times 10^{1}$ \\
\hline $\mathrm{SAR}_{10 \mathrm{~g}, \mathrm{limbs}}$ & $9.2 \times 10^{-7}$ & 2.2 & $1.7 \times 10^{3}$ \\
\hline $\mathrm{Antenna} 3$ & & & \\
\hline $\mathrm{E}_{\mathrm{RMS}}$ & $7.0 \times 10^{-5}$ & 1.7 & $1.5 \times 10^{3}$ \\
\hline $\mathrm{SAR}_{\mathrm{wb}}$ & $5.1 \times 10^{-2}$ & $9.5 \times 10^{-1}$ & $2.3 \times 10^{2}$ \\
\hline $\mathrm{SAR}_{10 \mathrm{~g}, \text { trunk }}$ & $2.3 \times 10^{-5}$ & 1.9 & $6.8 \times 10^{2}$ \\
\hline $\mathrm{SAR}_{10 \mathrm{~g}, \mathrm{limbs}}$ & $4.4 \times 10^{-1}$ & $6.6 \times 10^{-1}$ & $2.6 \times 10^{1}$ \\
\hline
\end{tabular}

Table 2 


\begin{tabular}{|c|c|c|}
\hline Frequency $(\mathrm{MHz})$ & $\operatorname{err}_{\text {low }}, \mathrm{err}_{\text {up }}$ using $\mathrm{SAR}_{\mathrm{wb}}(\%)$ & $\operatorname{err}_{\text {low }}, \mathrm{err}_{\text {up }}$ using $\mathrm{SAR}_{10 \mathrm{~g}}(\%)$ \\
\hline Antenna 1 & & $62.9,57.5$ \\
\hline 800 & $68.0,81.5$ & $56.5,48.8$ \\
\hline 900 & $60.4,56.2$ & $59.7,64.5$ \\
\hline 1800 & $55.1,81.7$ & $50.5,62.0$ \\
\hline 2600 & $60.4,71.1$ & $62.7,62.5$ \\
\hline Antenna 2 & $69.8,84.0$ & $57.4,45.3$ \\
\hline 800 & $62.7,59.0$ & $62.0,75.5$ \\
\hline 900 & $63.0,89.3$ & $68.5,95.2$ \\
\hline 1800 & $63.6,74.3$ & $70.6,69.1$ \\
\hline 2600 & & $57.4,44.1$ \\
\hline Antenna 3 & $72.5,122.2$ & $50.8,78.0$ \\
\hline 800 & $66.5,71.1$ & $52.0,40.6$ \\
\hline 900 & $67.1,93.8$ & \\
\hline 1800 & $62.2,81.5$ & \\
\hline 2600 & & \\
\hline
\end{tabular}

Table 3 


\begin{tabular}{|c|c|c|}
\hline $\begin{array}{c}\text { Number of radiating } \\
\text { patch antennas }\end{array}$ & $P_{\text {compl }}^{S A R_{w b}}(2600 \mathrm{MHz}, 300 \mathrm{~mm})(\mathrm{W})$ & $P_{\text {compl }}^{E_{r m s}}(2600 \mathrm{MHz}, 300 \mathrm{~mm})(\mathrm{W})$ \\
\hline 5 & 18.12 & 20.71 \\
\hline 11 & 21.22 & 19.69 \\
\hline
\end{tabular}

Table 4 


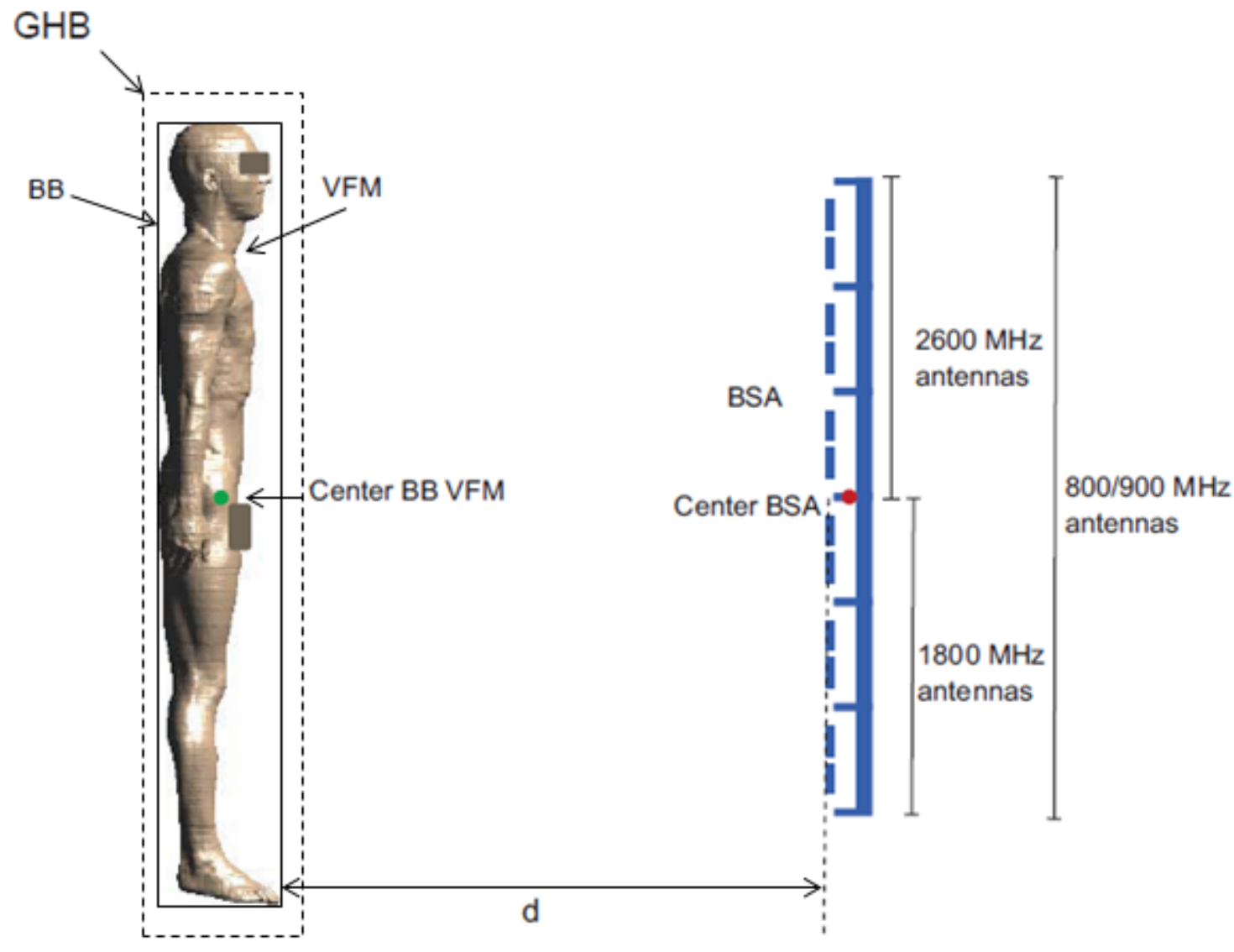

Figure 1 


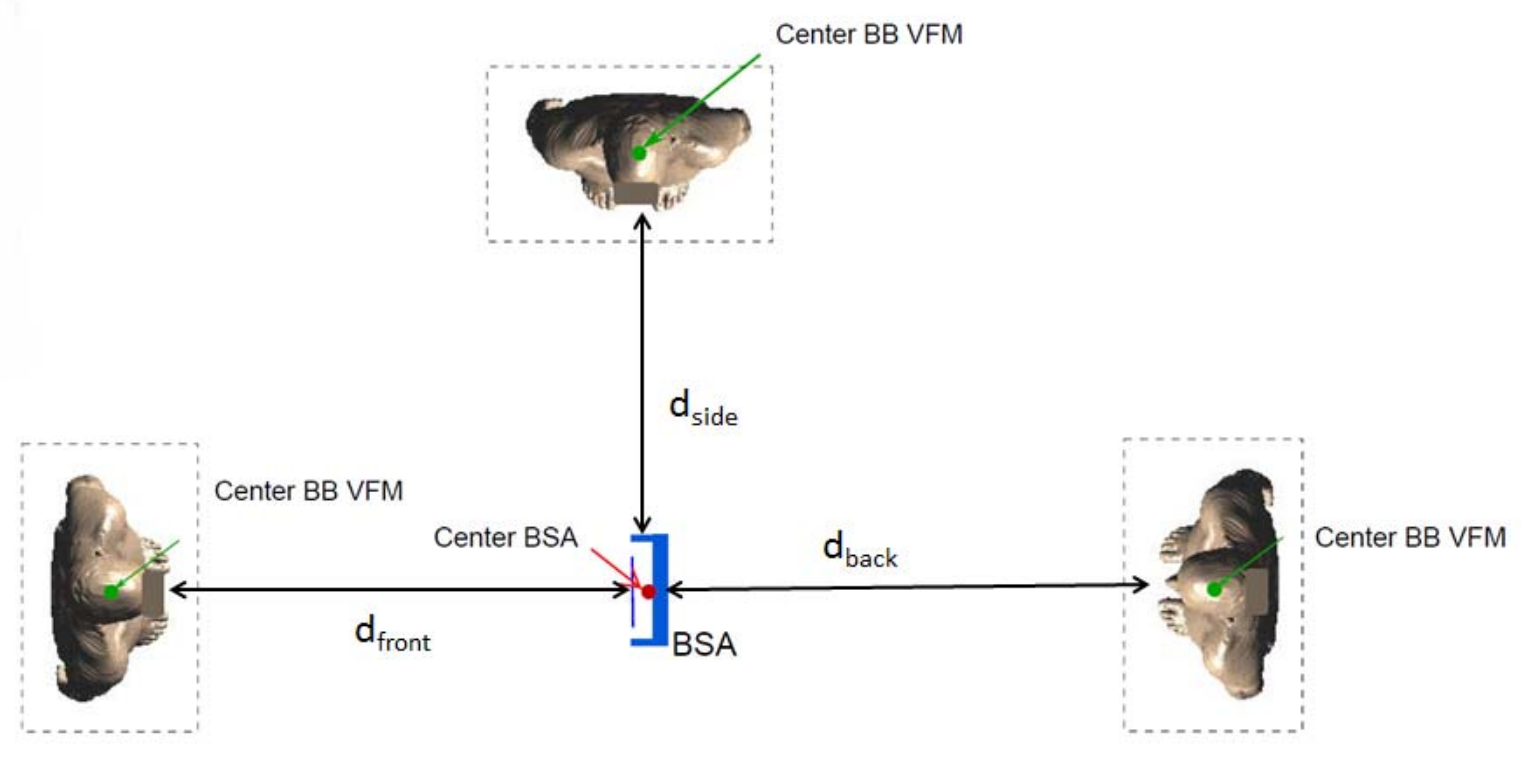

Figure 2 


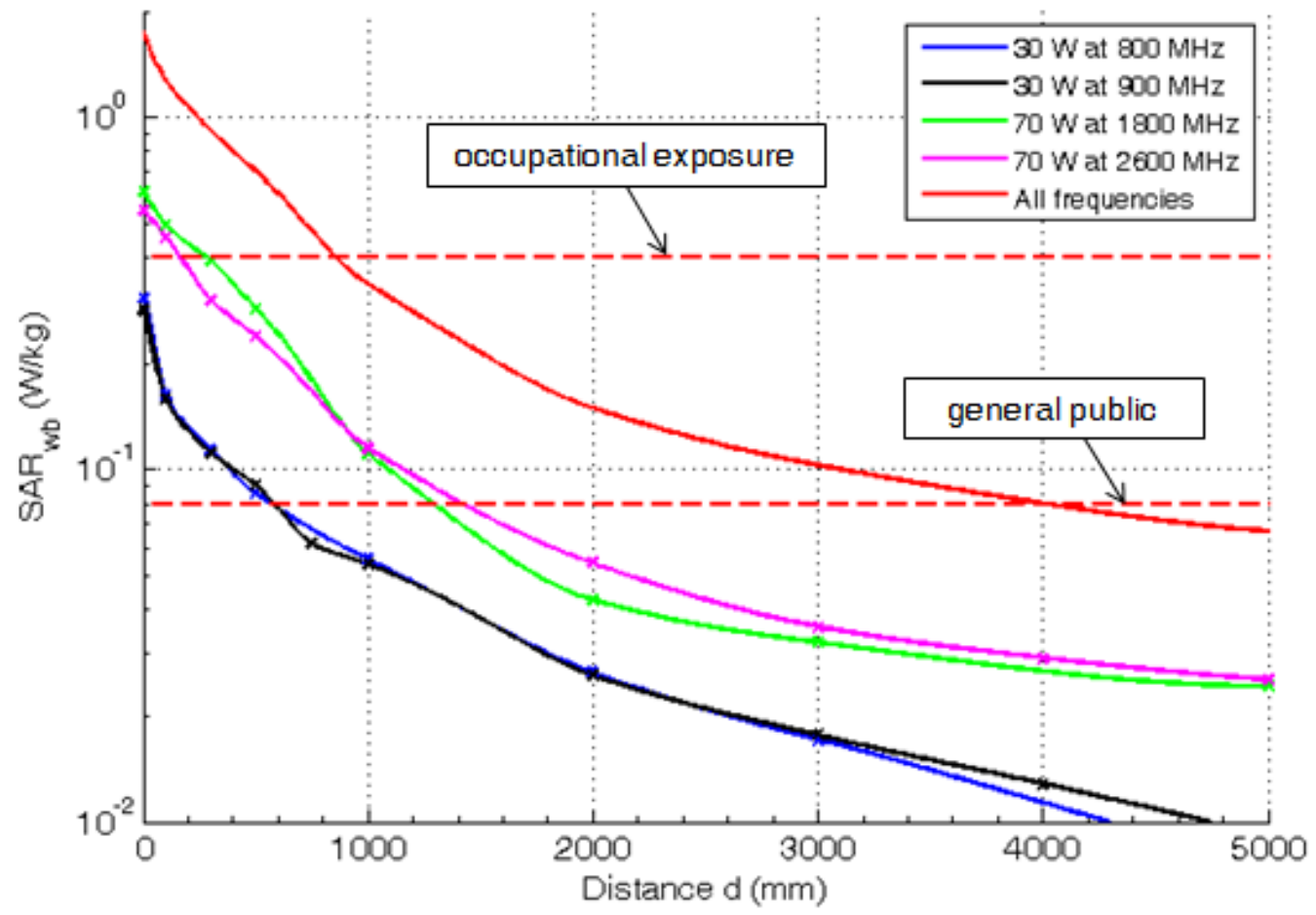

Figure 3 


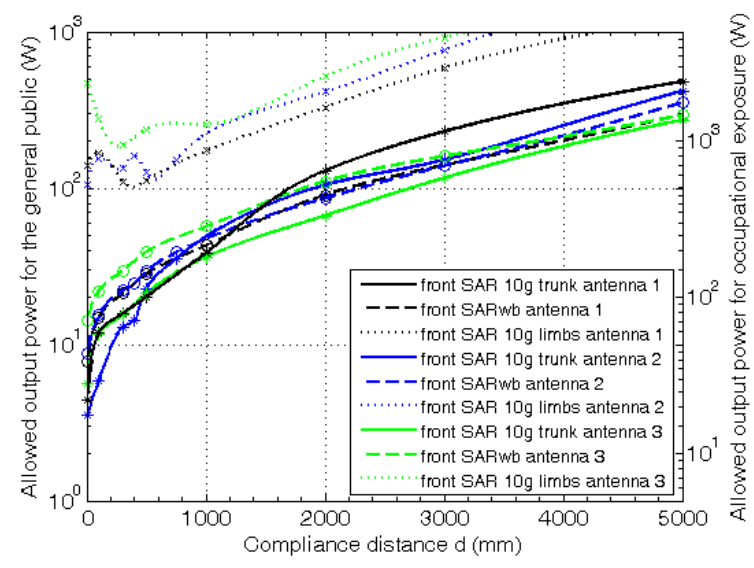

(a)

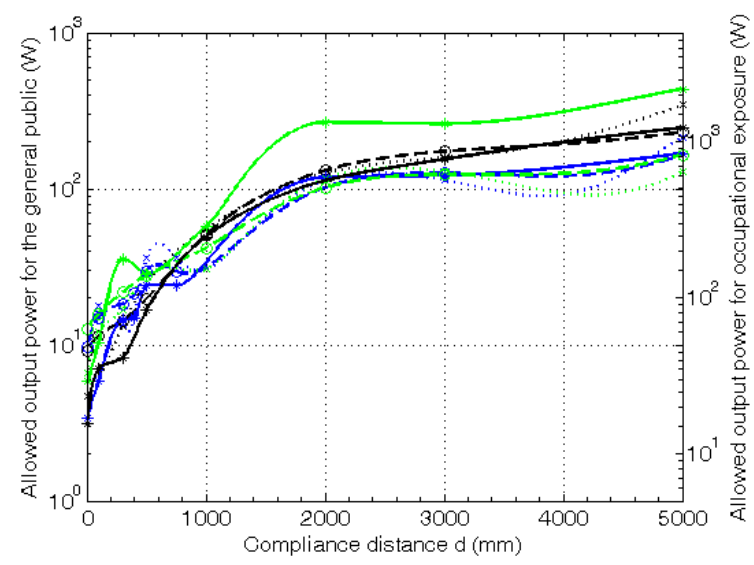

(c)

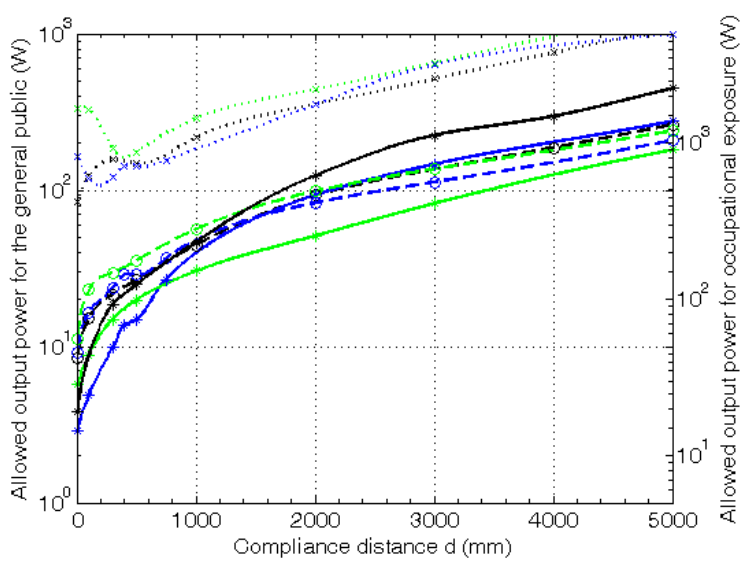

(b)

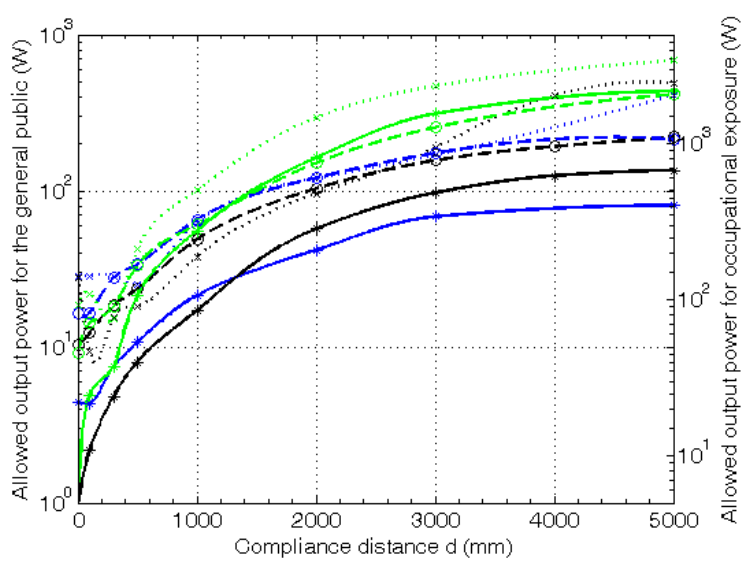

(d)

Figure 4 


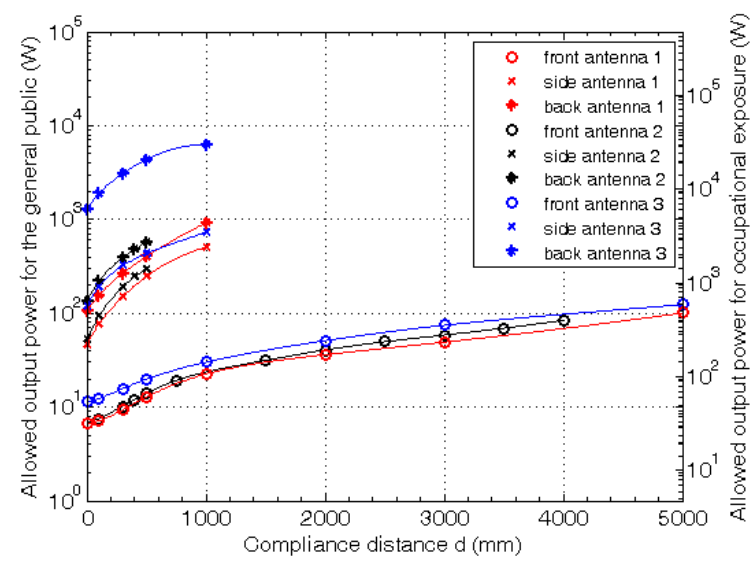

(a)

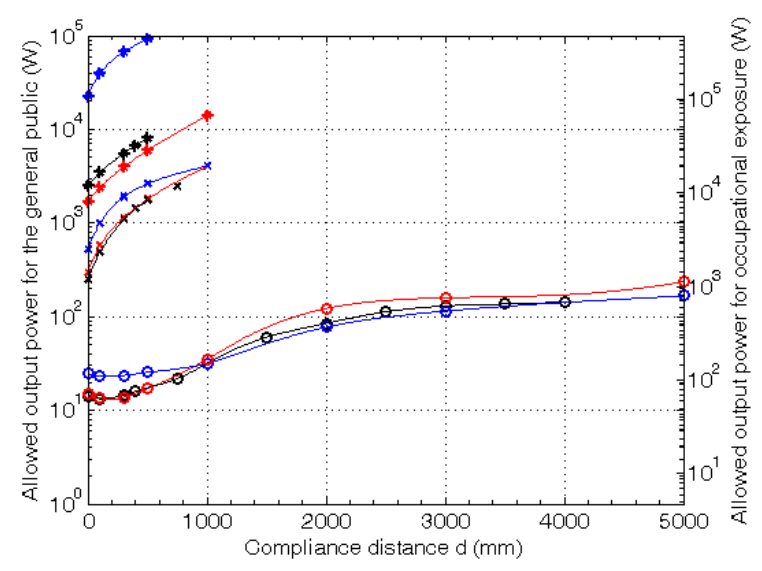

(c)

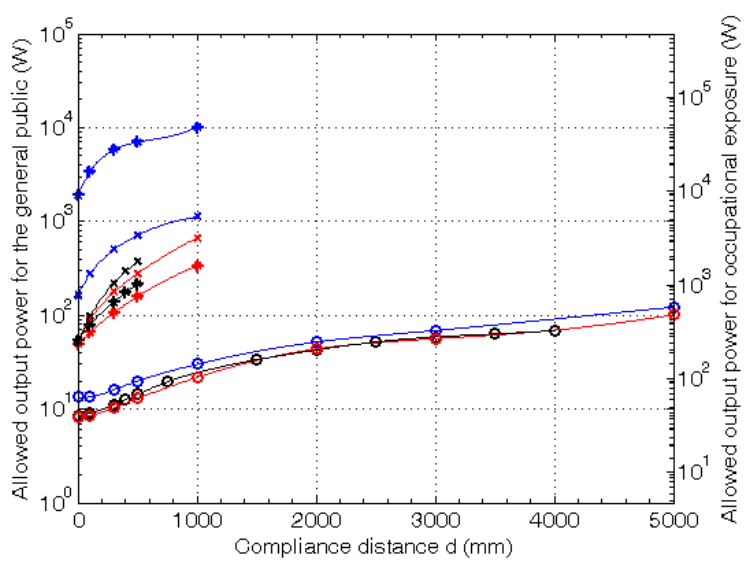

(b)

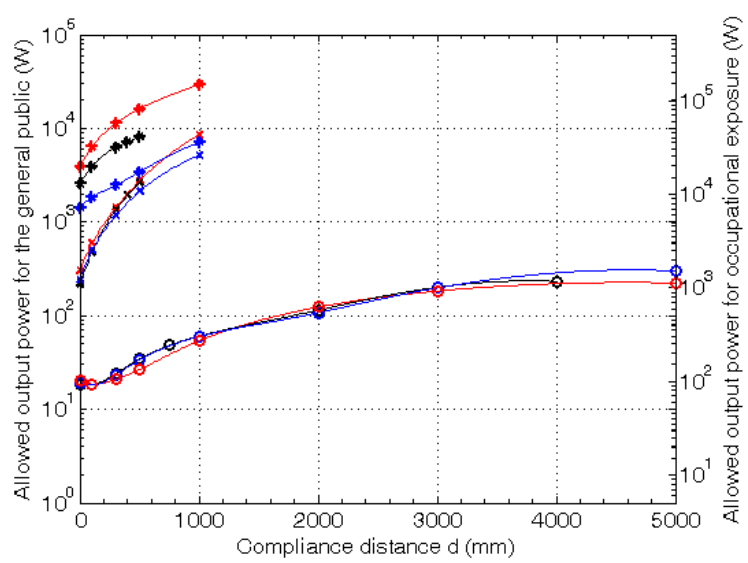

(d)

Figure 5 


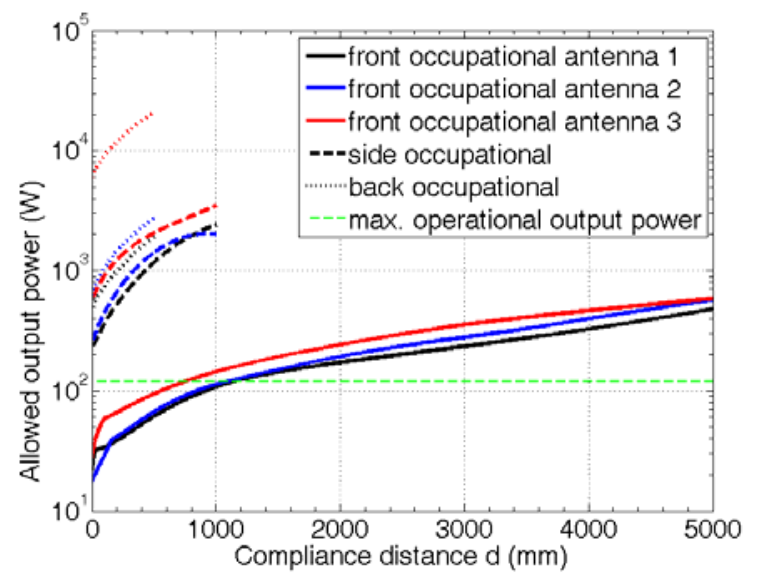

(a)

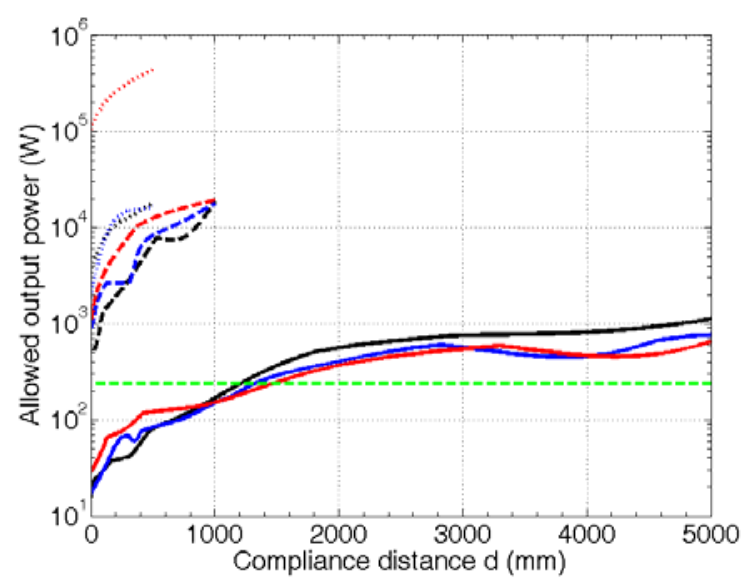

(c)

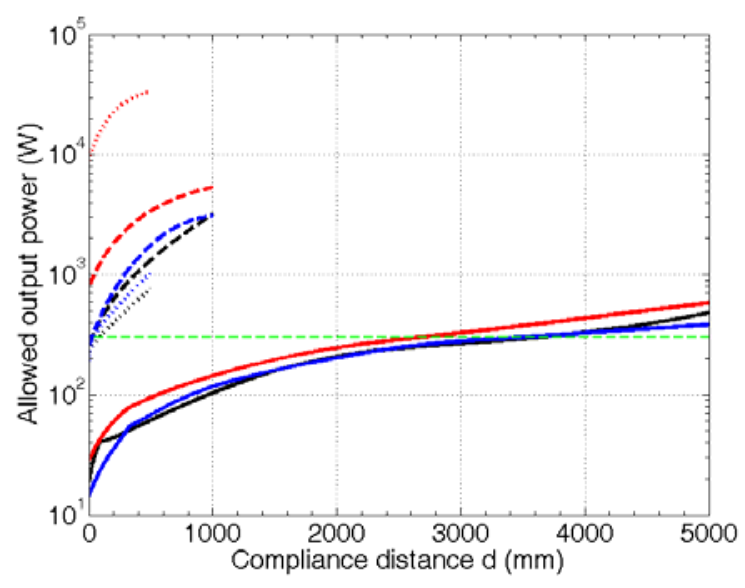

(b)

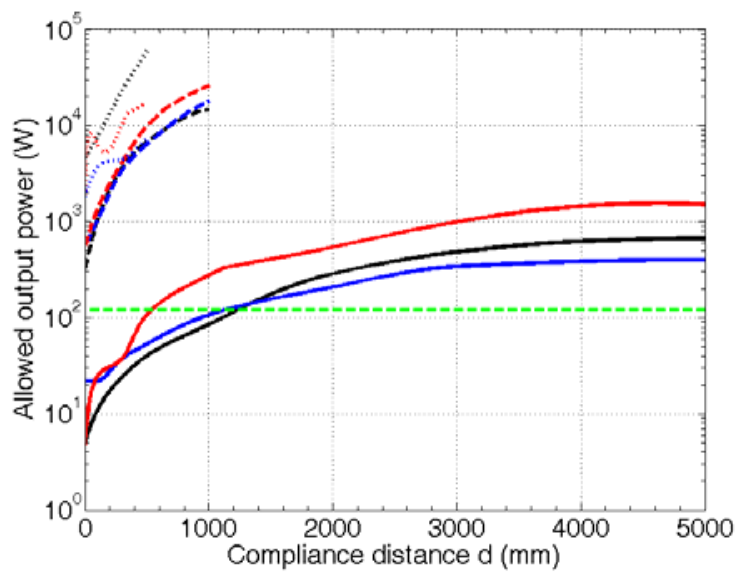

(d)

Figure 6 


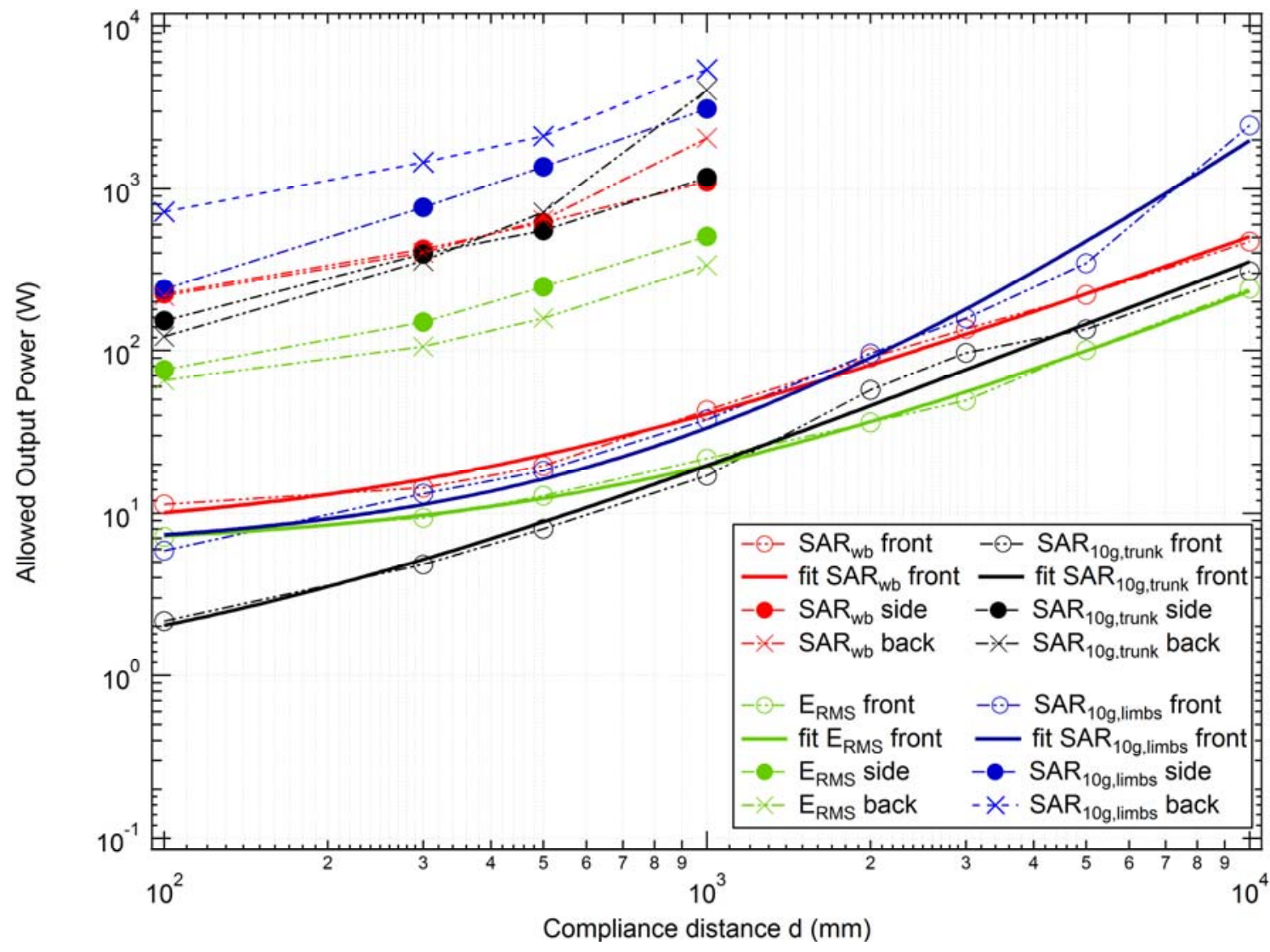

(a) 


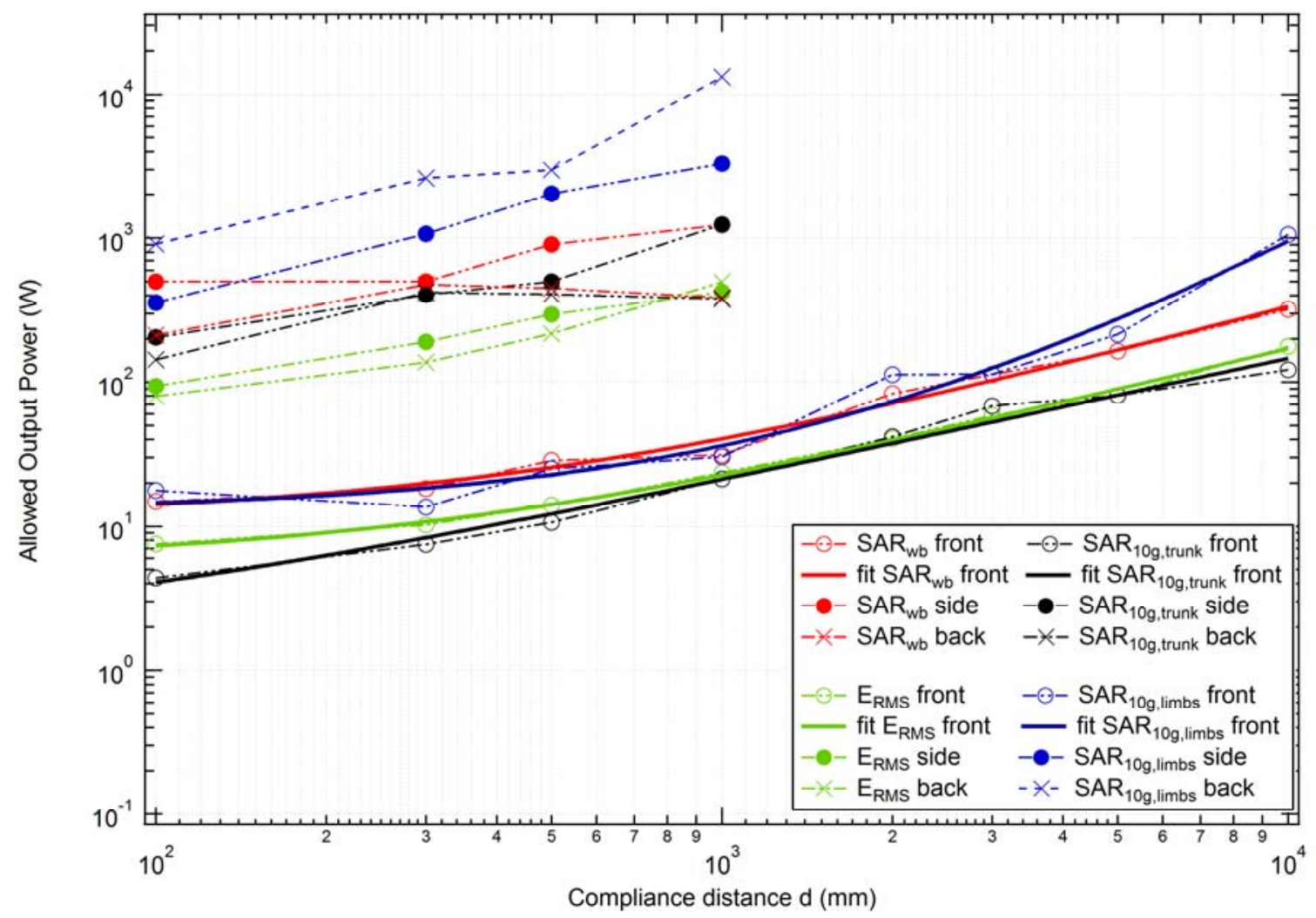

(b) 


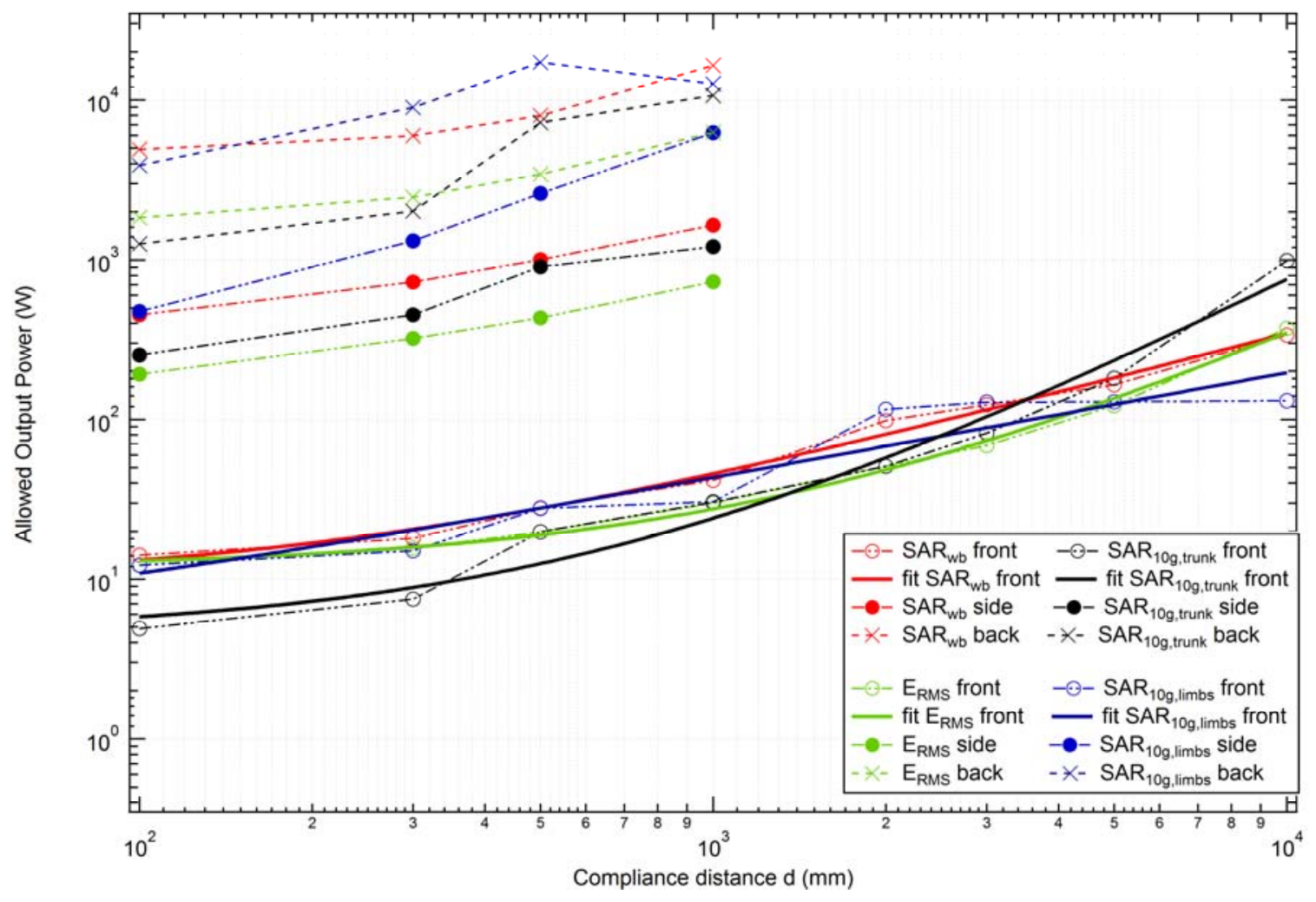

(c)

Figure 7 


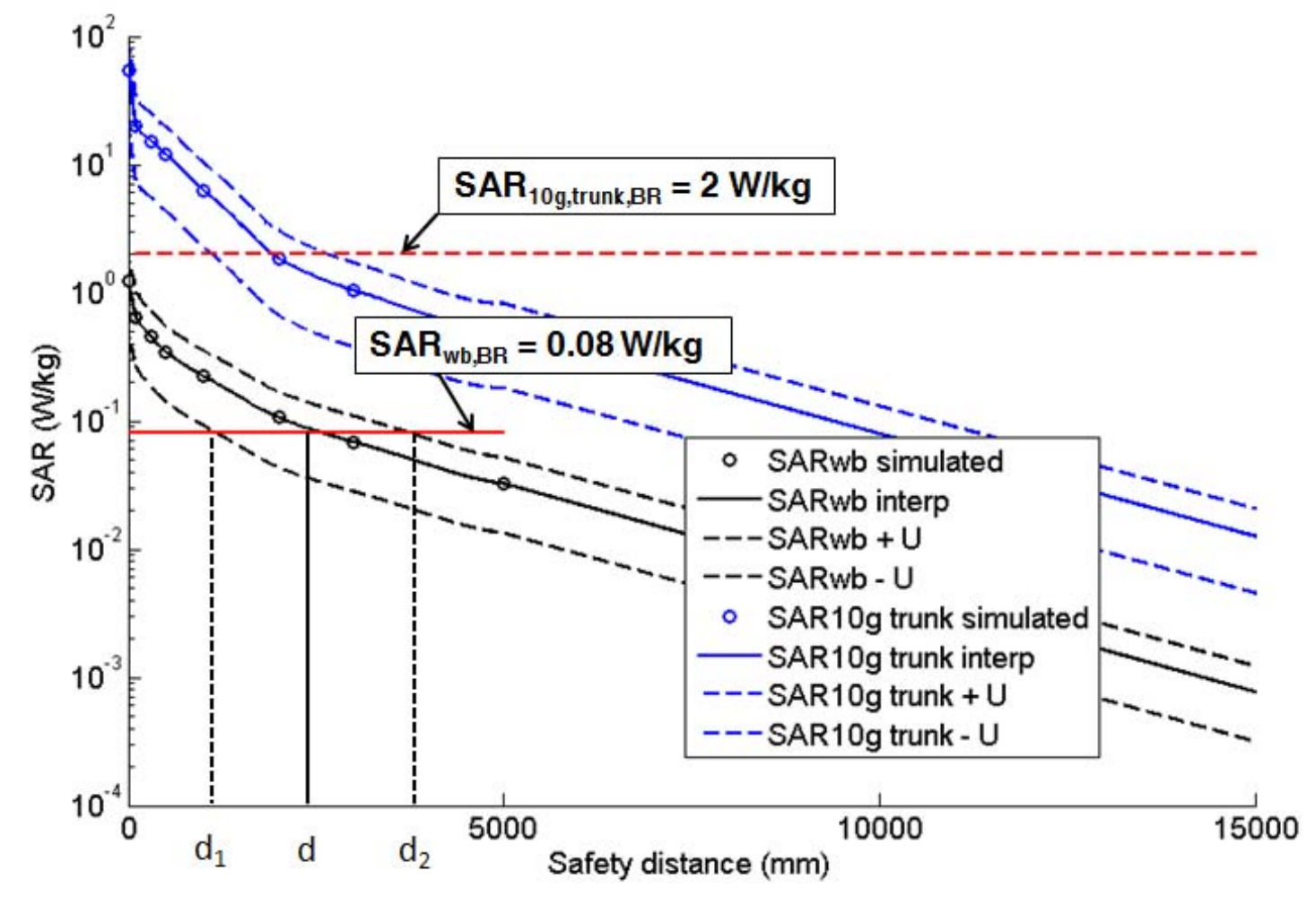

Figure 8 